Aproximações críticas entre os espetáculos Nós e $O$ ano em que sonhamos perigosamente

Critical approches between Nós and $\mathrm{O}$ ano em que sonhamos perigosamente

\title{
Pollyanna Diniz
}

Pollyanna Diniz Mestranda do PPG em Artes Cênicas da ECA-USP

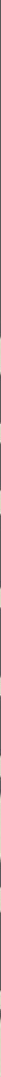




\section{Resumo}

O artigo traz possibilidades de análises críticas e aproximações entre os espetáculos Nós (2016), do grupo mineiro Galpão, em atividade desde 1982, e $O$ ano em que sonhamos perigosamente (2015), montagem mais recente do grupo de teatro pernambucano Magiluth, que possui doze anos de atuação. O texto problematiza questões relacionadas à teatralidade, ao teatro político, aos teatros do real, ao jogo como possibilidade de construção de uma teatralidade e à recepção.

Palavras-chave: Teatro político, Teatro de grupo, Teatros do real.

\section{Abstract}

The article presents possibilities for critical analyzes and approximations between the plays Nós (We, 2016), from Galpão, Minas Gerais, active since 1982, and $O$ ano em que sonhamos perigosamente (The year of dreaming dangerously, 2015), the most recent spectacle of the theater group Magiluth, from Pernambuco, which is active for twelve years. The text problematizes issues related to theatricality, political theater, theaters of the real, the game as a possibility of building a theatricality and reception.

Keywords: Political theatre, Group theatre, Theatres of the real.

Mesmo que nem todo mundo saiba que talvez a única função da arte seja exatamente esta, nos fazer passar da impotência ao impossível.

(Vladimir Safatle)

A urgência do diálogo com o nosso momento histórico de incertezas, fragmentações e desestruturação, inclusive com relação às instituições e à democracia, tem marcado parte da produção teatral contemporânea. É verdade que, ao nos referirmos ao teatro, o termo "político" pode ser tomado em sua ampla dimensão, e, sendo assim, ontologicamente, todo teatro seria político.

De todas as manifestações artísticas, a teatral é a mais claramente política, não apenas por se constituir numa representação pública como, exatamente, por ser uma representação pública. Espécie de espelho para a plateia, espécie de microcosmo para a cena, a relação entre ambas é plena de intenções de parte a parte e se apoia sobre duas instâncias decisivas: é dialógica e presencial. (MOSTAÇO, 2016, p. 3) 
Mesmo assumindo essa premissa, defendida também por Bernard Dort no texto “A vocação política”, escrito em 1965, não podemos deixar de perceber que, no Brasil, talvez a partir das manifestações de junho de 2013, a arte - e o teatro aqui especificamente - tenha voltado a se aproximar de maneira mais contundente da realidade política, econômica e social. Essa conjuntura tem funcionado como mola propulsora de projetos artísticos e estéticos, sejam espetáculos, performances ou leituras, levando-se em conta tanto forma quanto conteúdo, ampliando de maneira diferente e em graus diversos o que entendemos por dimensão ou alcance político do teatro.

Nesse sentido, não parece ser por acaso que muitos dos espetáculos que podem servir como exemplos dessa nova seara vinculada ao teatro político tenham sido criados justamente nas circunstâncias e no bojo do que chamamos de teatro de grupo. Para a autora lleana Diéguez Caballero (2011, p. 18), "abrir um espaço de reflexão sobre a constituição das atuais teatralidades liminares neste continente não só implica em desenvolver uma análise sobre o seu complexo hibridismo artístico, mas também considerar as suas articulações com o tecido social no qual estão inseridas".

De fato, a organização social de um grupo de teatro, pressupondo trabalho continuado, pesquisa de linguagem e inserção na realidade da política cultural brasileira, principalmente no que diz respeito à sustentabilidade de um coletivo, como disputa por editais e leis de incentivo e manutenção de sedes, influencia a construção de um arcabouço teórico-prático forjado no cotidiano e que se reflete também na cena. Quando um grupo brasileiro pensa a realidade do país, a América Latina, as questões que afetam a Europa ou o Oriente Médio, essas reflexões são carregadas, de maneira inerente, pelo contexto social no qual ele está incluído.

O Galpão, um dos pioneiros do teatro de grupo no país, criado em 1982 e sediado em Belo Horizonte, Minas Gerais, dedicou-se a pensar as dimensões políticas, éticas e sociais do tempo em que estamos vivendo em sua montagem mais recente, Nós (2016). O espetáculo torna-se especialmente potente ao conseguir levar ao palco não só uma visão macro, que discute, por exemplo, a violência, o preconceito ou o drama dos refugiados, mas também ao estabelecer camadas de significados que dizem respeito ao próprio grupo e ao lugar que esse coletivo de artistas decide ocupar, aos posicionamentos e inquietações diante de tantas questões. O nós do título refere-se também ao 
próprio Galpão, e insere na encenação a possibilidade de pensar como lidar com as subjetividades de cada integrante do grupo, como se deu essa manutenção por mais de três décadas de um coletivo artístico e de que forma, se existir, o futuro será construído.

A atriz Teuda Bara, 75 anos, integrante mais velha do Galpão, serve de metáfora para o próprio grupo e nós mesmos, espectadores. De que forma nos encaixamos nesta sociedade? Precisamos mesmo nos moldar? Quando nos tornamos descartáveis? Como reagir? Quais as maneiras para escapar à inércia? Como lidamos com as diferenças? Teuda Bara, que vinha ocupando papéis secundários nas últimas montagens do grupo, por uma questão de saúde, é uma mulher que absolutamente já não tem os padrões propostos pelo consumismo desenfreado. Idosa e gorda, sua serventia é colocada em questão ao longo de todo o espetáculo. Os nossos lugares-comuns são desestabilizados quando vemos a atriz passando batom, arrumando os cabelos, tirando a roupa, cantando, beijando, sendo submetida a um desgaste físico que julgamos extrapolar os limites. Há aí uma discussão sobre gênero, envelhecimento e sexualidade, mas também uma projeção disso sobre o grupo: depois de tantos anos, como envelhecer enquanto coletivo? Existe ainda sentido em estar juntos? O que mudou? Por que precisamos colocar à prova nossa serventia a cada espetáculo?

A repetição levada à exaustação é uma das características ressaltadas na montagem, principalmente na cena em que uma sopa é preparada pelo grupo. A utilização dessa repetição pode suscitar muitos caminhos. Como não temos clareza sobre as questões que nos cercam, estamos de alguma forma sempre nos repetindo, por exemplo. Já que também não há resposta, não conseguimos nos libertar de um círculo vicioso. A pergunta de Teuda Bara sintetiza: "Do que vocês estão falando mesmo?". O texto dito por Eduardo Moreira mais adiante abre chaves de leitura: "A gente está falando de não saber para onde ir, de paralisia; de repente sentir que a gente não existe. De você, de vocês. De intolerância. Estou falando de mim, profundamente de mim, aqui. Estou falando agora de nós, aqui. Para onde a gente vai?".

A dramaturgia delineia temas: violência policial, preconceito racial, como encaramos os desafios cotidianos, mas também convívio e afeto. Afinal, o preparo de uma sopa traz consigo a ideia de coletivo, de partilha, de comunhão. 
Expectativas que serão quebradas ao longo da encenação, já que a sopa será servida depois que Teuda Bara for expulsa de cena, uma sequência que explicita o descarte do outro como mercadoria.

Antes disso, justamente a cena da sopa, com os atores em torno de uma mesa conversando como se preparassem um jantar na cozinha da casa de um deles, vai ganhando contornos caóticos até ser interrompida pela explosão de uma bomba (símbolo de grande parte dos conflitos que acompanhamos no mundo). Os corpos nus - primeiro de Eduardo Moreira e logo em seguida de Teuda Bara - exibem as marcas do tempo e explicitam o desgaste, a fragilidade e, também, a potência. Se a construção imagética da cena é baseada efetivamente nesses corpos, que depois tomarão um banho de lama, como se reduzidos a pó, a dramaturgia abre-se novamente ao caos do cotidiano: trata desde a violência policial, passando por refugiados, o anúncio do fechamento de escolas em São Paulo, da tragédia ambiental em Mariana. A lama é usada como elemento sintetizador das tragédias que se sucedem.

Se o teatro político da década de 1960 trazia, principalmente em sua dramaturgia, um tom didático e panfletário com uma mensagem clara que precisava ser posta em cena, atualmente o que vemos, a exemplo do espetáculo do Galpão, é que as perguntas são mais frequentes do que as respostas. Os espetáculos incitam reflexões e debates, mas não se propõem a trazer perspectivas de mudanças claras. Geralmente, não há, na prática, transformação de realidades palpáveis. $O$ que pode ser encarado como um problema - já que a partir desses espetáculos não haveria de fato revolução - é também construção de um espaço que delega ao outro a mesma responsabilidade de pensar o presente. $O$ espaço é de construção conjunta, o que talvez interesse muito mais ao momento que vivemos do que fórmulas prontas de revoluções que não deram certo. Isso tem a ver com a própria definição de teatralidade, defendida por Josette Féral, relacionada não somente com os elementos da encenação - atores, espaço, objeto - e a ficção ou simulacro, mas com um processo, resultante da consciência tanto do performer quanto do espectador.

A condição da teatralidade seria, portanto, a identificação (quando é produzida pelo outro) ou a criação (quando o sujeito a projeta sobre as coisas) de um outro espaço, espaço diferente do cotidiano, criado pelo olhar do espectador que se mantém fora dele. Essa clivagem no espaço 
é o espaço do outro, que instaura um fora e um dentro da teatralidade. É um espaço fundador da alteridade da teatralidade. (FÉRAL, 2015, p. 86)

\section{Um grupo pernambucano}

Era 17 de junho de 2014, terça-feira, dia de jogo entre as seleções do Brasil e do México pela Copa do Mundo. Às 16h, quando os jogadores entrassem em campo na Arena Castelão, em Fortaleza, provavelmente as ruas das cidades por todo país estariam vazias, com escolas, repartições públicas e comércio fechados. No Recife, no entanto, centenas de pessoas saíram de suas casas não no intuito de acompanhar o jogo de futebol, mas para defender uma causa. A Polícia Militar de Pernambuco, incluindo policiais do Batalhão de Choque, Cavalaria e Canil, surpreendeu os manifestantes do movimento Ocupe Estelita, que estavam há 28 dias acampados numa área no Cais José Estelita, na região central do Recife, alvo de disputa judicial.

O movimento Ocupe Estelita congregou representantes da sociedade civil, profissionais liberais, professores, estudantes e artistas contrários ao Projeto Novo Recife, que previa um empreendimento imobiliário e empresarial no local, uma área de 10 hectares de grande valor comercial, incluindo a construção de doze torres. Ao reivindicar a destinação pública do cais José Estelita, levando em consideração questões como preservação histórica e ambiental e direito à cidade, o movimento contrariou e incomodou os interesses do grupo econômico responsável pelo projeto, um consórcio formado por empreiteiras. Apesar da disputa judicial, além de ter conseguido, até então, frear o projeto, o movimento Ocupe Estelita provocou o debate público sobre questões que dizem respeito, por exemplo, ao uso e ocupação da cidade, ao planejamento urbano e à especulação imobiliária.

Artistas de diversas linguagens, como música, cinema, teatro, literatura e artes visuais, fizeram parte efetiva da mobilização Ocupe Estelita. Mesmo quando a ocupação passou a acontecer fora dos muros onde ficam os antigos armazéns, depois da retirada dos manifestantes à força pela Polícia Militar, os artistas continuaram fortalecendo culturalmente o movimento, com shows, performances e criação de vídeos. Os integrantes do Magiluth, grupo teatral pernambu- 
cano formado em 2004, fazem parte da lista de artistas que se alinharam e se integraram ao movimento. No mês de abril de 2015, inclusive, fizeram uma apresentação do espetáculo de rua Luiz Lua Gonzaga (2012) em frente ao cais José Estelita, durante uma tarde repleta de ações culturais. A sessão, amplamente divulgada, estava na grade de programação do Trema! Festival de Teatro de Grupo do Recife, que, por três edições anuais, foi idealizado e produzido pelo Magiluth, reunindo grupos e coletivos de pesquisa vindos de várias regiões do país.

Para além das ações culturais de mobilização e manutenção/ampliação da força do movimento, as discussões fomentadas pelo Ocupe Estelita ecoaram na produção de vários artistas pernambucanos nos dois últimos anos. No caso do Magiluth, a reverberação mais direta se deu no espetáculo $O$ ano em que sonhamos perigosamente (2015). Embora não haja nenhuma citação nominal ao movimento, a especulação imobiliária ${ }^{1}$ é um dos temas que mais se sobressaem na montagem.

$\mathrm{Na}$ primeira parte do espetáculo², por exemplo, o ator Mário Sergio Cabral utiliza o próprio corpo como uma metáfora da cidade: mãos, braços, pernas, umbigo. Fala das zonas periféricas dos centros urbanos e de pontos que podem produzir tensão. Bem mais adiante, o ator repete o mesmo gestual, mas dizendo outro texto, de $O$ jardim das cerejeiras, uma das três peças do dramaturgo russo Anton Tchekhov que tiveram trechos incluídos em $\mathrm{O}$ ano em que sonhamos perigosamente.

O comerciante Lopakhin (Mário Sergio Cabral), sugere à endividada Liubov, a madame Ranévskai (Erivaldo Oliveira), proprietária das terras, que o cerejal e o terreno perto do rio sejam loteados e arrendados para casas de verão. Mas, para isso, ela teria que derrubar os prédios velhos, a casa e o cerejal.

1 O tema da especulação imobiliária também tem sido recorrente no cinema pernambucano. O diretor Kleber Mendonça Filho já parecia antever as discussões sobre ocupação urbana na capital pernambucana no filme $O$ som ao redor (2012). A temática foi tratada ainda mais diretamente em Aquarius, longa-metragem que participou do Festival de Cannes 2016. No filme, a personagem Clara, interpretada por Sônia Braga, é assediada por representantes de uma construtora que usam diversas estratégias para tentar fazer que ela venda o imóvel em que vive, único apartamento ainda ocupado num prédio dos anos 1940, numa das áreas mais nobres da cidade do Recife, a avenida Boa Viagem.

2 Nas entrevistas que deram pouco antes da estreia do espetáculo, os atores do grupo dividiam a montagem em três partes: na primeira, os atores/performers estariam em treinamento, buscando a construção de um momento belo; na segunda, encenam trechos de três obras de Tchekhov ( $A$ gaivota, $O$ jardim das cerejeiras e As três irmãs); e, na terceira parte, se dá a finalização do treinamento. 
Lopakhin: Você terá vinte e cinco rublos por ano para cada três acres de cada arrendatário, no mínimo, escuta meu conselho! Eu aposto que você não terá um lote vago no outono; todos serão arrendados. Em uma frase: está salva. Eu Ihe dou os parabéns. Mas, claro, você precisa começar a arrumar tudo, a preparar o terreno... Por exemplo, você terá que derrubar esses prédios velhos, essa casa, que não vale mais nada e terá que derrubar o cerejal...

Liubov: Derrubar? Meu caro amigo, você precisa me desculpar, mas eu não estou entendendo absolutamente nada. Se existe algo realmente interessante e impressionante em toda província, é nosso jardim das cerejeiras.

Lopakhin: A única coisa impressionante no cerejal é que é muito grande. Ele só dá cerejas a cada dois anos, e então não tem nada para fazer com elas, ninguém compra nenhuma.

Gaév: Esse Jardim é mencionado na Enciclopédia Russa. (TCHEKHOV, 1904)

A escolha do trecho de $O$ jardim das cerejeiras foi coerente e hábil, levando-se em conta especificamente o caso do cais José Estelita ou, de forma mais ampla, o país inteiro, a disputa econômica por espaços nas cidades, a gana financeira das construtoras, a verticalização. Não são poucos os casos em que as construções antigas, inclusive de valor histórico, são destruídas dando lugar geralmente a espigões, prédios cada vez mais altos.

Apesar de ter o real como elemento disparador da sua teatralidade, assim como o grupo Galpão em Nós, $O$ ano em que sonhamos perigosamente não trabalha com elementos comuns, por exemplo, histórias reais, arquivos, documentos, reportagens, como usados no teatro documentário. O objetivo não está na teatralização do real, mas em como conseguir tratar das complexas relações contemporâneas, sejam éticas, sociais, econômicas, financeiras, mesmo utilizando-se de uma dramaturgia fragmentada, que não tem como objetivo a narrativa ou a tentativa de racionalização do cotidiano.

Em $O$ ano em que sonhamos perigosamente, os atores/performers do Magiluth inserem-se no que Richard Schechner e Josette Féral defendem como teatro performativo que, em primeiro sentido, diria respeito à importância da ação:

Se seguirmos nosso primeiro impulso, duas fortes ideias estão no centro da obra performativa. De um lado, seu caráter de descrição dos fatos. Por outro, 
as ações que o performer realiza. A performance toma lugar no real e enfoca essa mesma realidade na qual se inscreve, desconstruindo-a, jogando com os códigos e as capacidades do espectador. (FÉRAL, 2015, p. 122)

A desconstrução e a fragmentação são características fundamentais tanto em Nós como na encenação do Magiluth. Há, por exemplo, nos dois casos, uma dificuldade explicitada em conseguir delimitar de que se trata o espetáculo. Por isso mesmo, no primeiro caso, a pergunta repetida inúmeras vezes é sobre o que eles estariam falando. De fato, não há uma temática única, mas desdobramentos a partir da crise - social, econômica, moral problematizando inclusive o próprio conceito de arte e, mais especificamente, de teatro.

Tal desconstrução passa por um jogo com os signos que se tornam instáveis, fluidos, forçando o olhar do espectador a se adaptar incessantemente, a migrar de uma referência a outra [...]. O performer instala a ambiguidade de significações, o deslocamento dos códigos, os deslizes de sentido. Trata-se, portanto, de descontruir a realidade, os signos, os sentidos e a linguagem. (FÉRAL, 2015, p. 122)

Tratando do Magiluth, a fragmentação do próprio tempo em que vivemos, inclusive no que diz respeito à complexidade de lidar diariamente com a profusão de conteúdos a que somos submetidos, se reflete na negação que o grupo empreende à narrativa como forma de compreensão do mundo em grande parte da montagem. O único momento em que isso se quebra é justamente quando eles recorrem a Tchekhov. Mas, ainda assim, são trechos de dramaturgias, retirados dos seus contextos, que tentam trazer maior inteligibilidade ao espetáculo, há poucas chaves de uma compreensão que pode ser entendida como linear, narrativa. No mais, o grupo envereda pela bricolagem de textos, teorias de pensadores e filósofos, filmes, músicas, compondo um mosaico que abre possibilidades de conexão semântica com o espectador.

Apesar de Patrice Pavis, no artigo intitulado "Uma redefinição do teatro político", afirmar que "esse retorno do referente social ou político vem acompanhado pelo prazer de contar e ouvir histórias, de apreciar o sentido dramático de uma fábula bem construída" (2013, p. 172), o que verificamos tanto em Nós quanto em $\mathrm{O}$ ano em que sonhamos perigosamente é que a opção pelo 
dramático não necessariamente está no cerne desse teatro interessado em refletir sobre as condições do presente.

Há um descarte deliberado do Magiluth, por exemplo, da tentativa de realizar ou mesmo se aproximar de explicações lógicas e conceituais. O espectador é responsável por traçar as suas próprias conexões a partir de provocações textuais, musicais e corpóreas propostas pelo grupo numa dramaturgia que tem nas repetições, cortes e interrupções a sua potência, o que também se verifica em Nós. O palco estabelece-se como campo de luta e de tensão. Como quando, por exemplo, um dos atores acusa o outro de utilizar uma roupa feita a partir de trabalho escravo; ou nos momentos em que todos se colocam em posição de barricada e jogam bombas imaginárias na plateia; ou mesmo na cena em que um performer (geralmente Pedro Wagner e Mário Sergio Cabral, irmãos na vida real) tenta ensinar ao outro o que é beijar na boca, uma sequência absolutamente fria e mecânica, que passa ao largo do afeto e acaba por levar, ao contrário, à violência. O que vemos é que a multiplicidade das possibilidades estéticas apreendida desde a década de 1980 agora se mostra à disposição dos grupos que se dedicam a investigar como se dão as novas relações sociais, econômicas, políticas e de que forma podemos dialogar - interferir, talvez, nem seja a palavra correta - nessa conjuntura.

\section{Corpos em desajuste}

A experimentação dos limites entre realidade e ficção, proposta visualizada em muitos trabalhos contemporâneos que podem ser considerados vinculados ao teatro político, seja pela temática, pelos modos de produção e pelas intencionalidades, também está posta em cena no espetáculo $O$ ano em que sonhamos perigosamente. Essas fronteiras entre realidade e ficção estão borradas na cena do Magiluth desde o início do espetáculo, quando o espectador compreende que os atores estão no palco realizando uma espécie de ensaio, de treinamento, justamente para uma apresentação. Por algumas vezes, até o fim da montagem, um dos atores tenta achar o tom correto da saudação inicial do suposto espetáculo, dizendo que eles são o grupo Magiluth, pedindo para que as pessoas desliguem - ou não - os telefones celulares, que no dia em que eles estrearem de fato, ele saberá dizer em que data estão. 
Os atores perseguem ao longo de toda a peça uma estreia que, na condução da dramaturgia, não acontece. Eles estão em cena, mas não submetidos a uma obra acabada, e sim jogam e experimentam as possibilidades de corpos, movimentos e situações. Nesse sentido, é significativa a importância que a dança, o esporte e o treinamento físico assumem na encenação. Há, por exemplo, cenas com longas coreografias, de corporeidades destoantes, que não se enquadram nos padrões de corpos acostumados ao exercício. $A$ presença desses corpos performativos no palco, uma presença que se configura política, já se constitui um ato de enfrentamento; na consciência da utilização deles como instrumentos de trabalho, de repetição, de exaustão, em muitas sequências em que força e explosão são solicitadas.

No livro A nova razão do mundo: ensaios sobre a sociedade neoliberal, Christian Laval e Pierre Dardot defendem que o neoliberalismo se constitui como uma nova racionalidade, que determina não só políticas de estado ou modos de produção, mas se refere a um sistema normativo, que expandiu a lógica do capital para todas as relações sociais. Os autores colocam o "sujeito empresarial" como figura central dessa lógica, explicando como cada indivíduo funcionaria como uma empresa. A argumentação utiliza também o esporte e a competição para tratar do "empreendedor de si,' produzido para "ganhar" e ser "bem-sucedido".

Trazendo esse contexto para o Magiluth, o grupo amplifica contradições ao assumir no palco a imperfeição dos corpos e coreografias, contrastando com a lógica da perfeição advinda da repetição solicitada pelo esporte levada às cenas, aos movimentos ou mesmo aos textos ditos pelos performers. Se na revolução industrial o movimento repetitivo está diretamente relacionado à exploração da mão de obra, à especialização do trabalho e à falta de consciência sobre o processo como um todo, o neoliberalismo conseguiu realizar a inversão de associar a repetição pelo "sujeito empresarial" à perfeição, ao sucesso e à multiplicação do capital.

Em O ano em que sonhamos perigosamente, fica claro o espírito de concorrência, próprio do neoliberalismo, mas também as suas consequências, como a possibilidade da falha, do erro e da própria perda. Muitas vezes, o movimento de um dos atores é interrompido pelo companheiro de palco, que inicia outra ação e consegue captar para si a atenção e os esforços dos demais. O movimento proposto pelo anterior pode ou não ser retomado, se 
ele for capaz de, "concorrendo" com os demais, mostrar que faz sentido que a ação dele seja resgatada na sequência.

Nesse sentido, uma das características mais interessantes da peça é o fato de ela se mostrar, na prática, um roteiro que permite combinações múltiplas. Se o teatro já lida com o fato da impossibilidade da repetição, do efêmero, do inédito, aqui isso se explicita de forma ainda mais radical, embora essa característica só fique clara para quem assiste à peça mais de uma vez. Há algumas cenas e sequências que podem ser consideradas fundamentais para a encenação, como uma coreografia na primeira parte, as cenas das peças de Tchekhov e a cena final da montagem. Mas o que pode acontecer entre essas sequências -nítido quando acompanhamos mais de uma sessão - não é definido previamente.

Essa proposta de encenação se torna possível graças a um dos pilares do trabalho do Magiluth, recorrente em várias peças do grupo, em algumas de forma mais explícita ao público do que noutras, que eles chamam de jogo. A ideia é fundamental para compreender a teatralidade que o grupo procura estabelecer: "[...] um ator que não negligencia o momento que está vivendo. Aquele momento não pode ser pré-estabelecido, cristalizado" (CASTRO, 2015). Aqui a noção de jogo está distanciada do esporte competitivo citado anteriormente, quando tratamos do neoliberalismo e da sua lógica concorrencial, mas mantém, na realidade, uma relação com o que Johan Huizinga conceitua, já nas primeiras décadas do século XX, como jogo cultural:

uma ação livre, sentida como fictícia e situada fora da vida corrente, e no entanto capaz de absorver completamente o jogador; é uma ação desprovida de todo interesse material e de toda utilidade, que se pratica em um tempo e um espaço expressamente circunscritos, desenvolve-se segundo uma ordem e com regras dadas. (HUIZINGA, 2012, p. 16)

\section{Político e real}

As experiências do Magiluth, com o espetáculo $O$ ano em que sonhamos perigosamente, e do grupo Galpão, com Nós (abrindo o leque, podemos pensar na Companhia Brasileira, com Projeto brasil ou no Espanca!, com Real), podem nos oferecer indícios de como o teatro de grupo no Brasil está tentando estabele- 
cer novas relações de aproximação com o real, não necessariamente vinculadas ao teatro documentário ou à reprodução da realidade em cena, e, especificamente, com o político. Não existe, como já dito, a preocupação em tentar dar conta totalmente da amplitude e da complexidade da realidade, o que seria inviável, mas de levantar questionamentos e propor olhares específicos para determinados temas, trazendo à cena problematizações e possibilidades de apreensões.

Nesse sentido, para o Magiluth, por exemplo, não importa aos atores a opção pelo dramático - em $O$ ano em que sonhamos perigosamente, o teatro dramático não daria conta de lidar com a multiplicidade de assuntos e enfoques, completamente fragmentados e dispersos, trazidos à cena. Também não faz sentido ao grupo a representação de um personagem nos moldes tradicionais, mesmo quando encenam os textos clássicos de Tchekhov, mas de que maneira o ator/performer pode imprimir concomitantemente presença e sentido à experiência estética compartilhada com o espectador.

Para Ulrich Gumbrecht (2011), a experiência estética gera simultaneamente presença e sentido. Se nossa sociedade ocidental está cada vez mais ligada à produção de sentido, o teórico alemão, por sua vez, coloca a presença como uma forma de resgatar as dimensões corpóreas e espaciais da existência, fundamentais quando pensamos tanto em Nós quanto no espetáculo $O$ ano em que sonhamos perigosamente. No caso do Magiluth, a proposta de encenação, inclusive, se apoia muito mais na presença dos atores como corpos políticos em cena; talvez pela fragilidade da construção da dramaturgia, o que não acontece no caso do Galpão, em que há um equilíbrio maior dos elementos que constroem a encenação.

$\mathrm{Na}$ análise da peça do Magiluth, inclusive, há ainda muitas questões que dizem respeito ao público para serem enfrentadas e verificadas quando decidimos esmiuçar os meandros do espetáculo. Uma delas é a maneira como o espectador se aproxima e acessa o real, e concomitantemente o político, na proposta de teatralidade assumida pelo Magiluth. Isso não tem a ver com a participação direta do público no espetáculo, inclusive fisicamente ou ajudando a compor a dramaturgia, como já aconteceu em montagens anteriores do grupo. Em Aquilo que meu olhar guardou para você (2012), por exemplo, o público era levado ao palco, havia a construção de uma relação de afetividade tanto a partir da dramaturgia quanto da performance dos atores. 
Em $O$ ano em que sonhamos perigosamente, ao contrário, as relações com o espectador seguem a distância proposta pela quarta parede. É como se o grupo ignorasse a presença do outro, a quem, de fato, se destina a montagem; mas, contraditoriamente, essa opção parece reforçar o sentimento de desamparo diante de tudo que está sendo apresentado no palco, fazendo que a força e a virulência da performance cheguem inclusive de forma mais radical e potente ao espectador, o que ainda é uma hipótese a ser comprovada. Ainda assim, permanecem questionamentos para serem esclarecidos a posteriori com relação à recepção, diante da fragmentação da dramaturgia. Não sendo o entendimento analítico claro do espetáculo uma proposta do grupo, no entanto, o caminho da recepção se mostra uma aposta profícua no risco, tal como trata Vladimir Safatle ao se debruçar sob a obra Leap into the void (1960), de Yves Klein:

[...] Quem toca o impossível paga um preço. Há o chão à nossa espera, o acidente, a quebra certa e segura como a dureza do asfalto. [...] Há momentos em que os corpos precisam se quebrar, se decompor, ser despossuídos para que novos circuitos de afetos apareçam. (SAFATLE, 2015, p. 44).

\section{Referências bibliográficas}

CASTRO, G. Entrevista concedida a P. Diniz e I. Moura. 4 ago. 2015.

CABALLERO, I. D. Cenários liminares: teatralidades, performances e política. Trad. Luis Alberto Alonso e Angela Reis. Uberlândia: EDUFU, 2011. DORT, B. 0 teatro e sua realidade. São Paulo: Perspectiva, 2010. FÉRAL, J. Além dos limites: teoria e prática do teatro. São Paulo: Perspectiva, 2015. FERNANDES, S. Teatralidades contemporâneas. São Paulo: Perspectiva, 2010. GUMBRECHT, U. Produção de presença: o que o sentido não consegue transmitir.

Trad. Ana Isabel Soares. Rio de Janeiro: Contraponto/PUC-Rio, 2011.

HUIZINGA, J. Homo ludens: o jogo como elemento da cultura, 7. ed. São Paulo: Perspectiva, 2012.

LAVAL, C.; DARDOT, P. A nova razão do mundo: ensaios sobre a sociedade neoliberal. São Paulo: Boitempo, 2016. (Coleção Estado de Sítio)

MOSTAÇO, E. À guisa de editorial: desafios do teatro político. Urdimento, Revista de Estudos em Artes Cênicas, Udesc, Florianópolis, v. 1, n. 26, p. 3-8, 2016.

PAVIS, P. Uma redefinição do teatro político. Sala Preta, São Paulo, v. 13, n. 1, p. 171175, 2013.. 
SAFATLE, V. O circuito dos afetos: corpos políticos, desamparo e o fim do indivíduo. São Paulo: Cosac Naify, 2015.

TCHEKHOV, A. 0 jardim das cerejeiras. Trad. Jorge Maricato. Disponível em: <http://maricato.net/m/textos/O_Jardim_das_Cerejeiras-v1.3.pdf >. Acesso em: 20 ago. 2015.

Recebido em 21/05/2017

Aprovado em 22/05/2017

Publicado em 14/07/2017 